\title{
VIOLÊNCIA SEXUAL E ABORTAMENTO COMO DIREITO: CONCEITOS, CONFLITOS E SIGNIFICADOS
}

\author{
SEXUAL VIOLENCE AND LEGAL ABORTION: CONCEPTS, CONFLICTS AND MEANING
}

\author{
Suelen Marçal Nogueira \\ Mestre em Ciências Ambientais e Saúde- PUC-GO. \\ Docente da Facer Faculdades - Ceres - GO. Brasil. \\ Docente Universidade Estadual de Goiás - Câmpus Ceres. \\ Email:suelenmnogueira@yahoo.com.br
}

\section{Priscila Silva de Jesus}

Faculdade de Enfermagem, Universidade Estadual de Goiás - Câmpus Ceres.

Email: pripri_92@ hotmail.com

\section{Endereço para correspondência:}

Av. Brasil, S/N, Qd. 13 Morada Verde - GO, Fone: (62) 3323-1040,

E-mail: suelenmnogueira@yahoo.com.br

\section{RESUMO}

Introdução: A violência sexual é um agravante de saúde pública e um problema mundial de caráter histórico e social que pode levar a inúmeras consequiências à mulher. Entre todos os efeitos ocasionados pela violência sexual encontra-se a gravidez e os transtornos como a decisão de continuar ou não com a gestação de um filho do agressor. Objetivo: O estudo objetivou analisar os conceitos, os conflitos e os significados da violência sexual e do abortamento legal. Metodologia: Trata-se de uma pesquisa do tipo qualitativa e descritiva com análise bibliográfica de produções sobre a violência sexual e o abortamento como direito. Resultados e Discussão: A liberdade sexual aumentou a incidência de casos de violência sexual e paralelamente ocorreu o aumento do índice de abortamentos cometidos no mundo. Após a mulher ter passado pelo sofrimento do abuso sexual ela se depara com consequências físicas como os traumas genitais e extragenitais, Doenças Sexualmente Transmissíveis (DST's) e ainda a gravidez indesejada. $\mathrm{O}$ aborto decorrente de estupro se enquadra em aborto eletivo previsto em lei como expõe o artigo 128 do Código Penal Brasileiro. Além das possíveis consequências físicas como infecção, hemorragia e esterilidade um aborto costuma provocar crises de arrependimento e culpa, com reações psicológicas, sociais e biológicas. Conclusão: A violência sexual atinge números alarmantes no Brasil e no Mundo e que o abortamento é um direito da vitima em casos de estupro, porém o ato pode gerar conflitos internos e somar maiores consequiências às vitimas.

Palavras-chave: Abortamento legal, Violência sexual, Vítima.

\section{ABSTRACT}

Introduction: Sexual violence is an aggravating public health and a worldwide problem historical and social which can lead to numerous consequences to the woman. Among all the effects caused by sexual violence is pregnancy and disorders such as the decision to continue 
or not with the pregnancy. Objective: The study aimed to analyze the concepts, conflicts and meanings of sexual violence and legal abortion. Methodology: This is a survey of qualitative and descriptive literature review with productions debating about sexual violence and legal abortion. Results and Discussion: Sexual freedom increased the incidence of sexual violence and in addition there was an increase of miscarriages index committed in the world. After the woman has gone through the suffering of sexual abuse she faces physical consequences such as genital and extragenital trauma, sexually transmitted diseases and even unwanted pregnancy. Abortion due to rape falls into elective abortion provided by law and exposes the article 128 of the Brazilian Penal Code. In addition to possible physical consequences such as infection, bleeding and sterility an abortion usually causes regret and guilt crises, with psychological, social and biological reactions. Conclusion: Sexual violence has reached alarming numbers in Brazil and in the world and that abortion is legal of the victim in cases of rape, but the act can generate internal conflicts and add greater consequences for the victims.

Keywords: Legal Abortion, Sexual Violence, Victim.

\section{INTRODUÇÃO}

A violência sexual é um problema mundial de caráter social e histórico que toma proporções extraordinárias e assustadoras deixando marcas traumáticas e indeléveis a vítima. No Brasil, a cada 12 segundos uma mulher é estuprada, em São Paulo a média atingiu 37 estupros por dia em 2013 (MENICUCCI, 2013; BENITES, 2013).

Segundo o Fórum Brasileiro de Segurança Pública em 2010 foram registradas ocorrências policiais de 1.141 estupros em Goiás. Em 2011 foram registradas 1.395 ocorrências no estado, sendo que em 2010 a taxa era de $19 \%$ e em 2011 de 21, $8 \%$ aumentando em um ano 2,8\% de ocorrências policiais do crime de estupro (BRASIL, 2012).

A violência sexual contra mulheres resulta em grande impacto na vida produtiva e na saúde física e psíquica das que a sofreram, assim como na de seus filhos e demais membros da família. Além do transtorno que a violência sexual traz à mulher, também há os produtos deste ato, como traumatismos físicos, ameaças psicológicas e físicas pelo autor da violência, doenças sexualmente transmissíveis não virais, hepatites virais, infecção pelo HIV, gravidez decorrente da violência sexual sofrida, entre outros transtornos como a decisão de continuar ou não com a gravidez (BRASILa, 2011).

O dilema social do direito legal sobre abortamento em mulheres vítimas de violência sexual o entendimento ético, moral e jurídico do tratamento dado a esta mulher e sua posição frente a esta situação norteiam e estimam esta pesquisa analítica. 


\section{METODOLOGIA}

Trata-se de um estudo de revisão bibliográfica de aspecto qualitativo e descritivo sobre a violência sexual sofrida por mulheres e os conceitos e conflitos do abortamento como direito.

Foram utilizados os descritores: violência sexual, abortamento legal e vitima. A Biblioteca Virtual de Saúde - BVS foi utilizada como fonte de pesquisa para a seleção dos trabalhos científicos que se enquadravam no tema. Foi também realizada uma busca manual de textos jurídicos que tratam do assunto.

Os critérios de inclusão foram: estudos publicados nos últimos 15 anos e realizados no Brasil, no idioma português, dadas as peculiaridades jurídicas, éticas e morais que envolvem a questão do abortamento em cada país. Foram também selecionados artigos que expunham relação entre abortamento consentido em decorrência à violência sexual.

Foram excluídos artigos que discutem sobre o aborto clandestino, o uso indiscriminado de medicamentos abortivos e suas consequências, a violência sexual infantil e a violência doméstica.

\section{RESULTADOS E DISCUSSÃO}

A violência sexual se insere no contexto atual com grande relevância em virtude de sua importância social e da alta incidência, atingindo patamares alarmantes. De acordo com a Organização Mundial da Saúde a violência é conceituada como:

O uso intencional de força física ou do poder, real ou em ameaça, contra si próprio, contra uma pessoa, ou contra um grupo ou uma comunidade que resulte ou tenha possibilidade de resultar em lesão, morte, dano psicológico, deficiência de desenvolvimento ou privação de liberdade (BRASILa, 2011, p. 11).

A violência pode ser identificada ou subclassificada de acordo com os seres atingidos por tal, assim temos a violência contra grupos etários (crianças, adultos e idosos), contra raça (negros, albinos) e contra gêneros como a violência contra o homossexual e violência contra a mulher.

As Nações Unidas definem violência contra a mulher como qualquer ato de violência baseada no gênero que resulte ou possa resultar em dano físico, sexual, mental ou sofrimento para a mulher, inclusive ameaças destes atos, repressão ou reclusão da liberdade de escolha, ocorrida em público ou na vida privada (BRASILa, 2011). 
Dentre estas violências o estupro é a quinta causa de agressão que às mulheres enfrentam. De acordo com o artigo 213 do Código Penal brasileiro cuja redação determinada pela Lei $\mathrm{n}^{\circ}$ 12.015/2009 o estupro é definido como: “Constranger alguém, mediante violência ou grave ameaça, a ter conjunção carnal ou a praticar ou permitir que com ele se pratique outro ato libidinoso" (IBGE, 2013; VADE MECUM, 2010, p. 564).

Esta perspectiva de violência se contextualiza com a história da sociedade em que estão inseridos os papéis sociais dos gêneros. Assim, estes no decorrer dos anos adquiriram funções tradicionais herméticas que durante séculos permaneceram inexoráveis. A imagem feminina está ligada a passividade, a fragilidade, a emoção, a submissão. A imagem masculina liga-se a atividade, a força, a racionalidade, a dominação, como se fossem atributos natos de cada gênero (BRASILa, 2011).

Mediante a violência sexual se encontram inúmeras consequências, dentre estas a transmissão de doenças infectocontagiosas como a AIDS, hepatite B e C, DSTs, gravidez indesejada; problemas psicológicos tais como, trauma pós estupro, fobias, depressão, suicídio e, abortamento; este, por fim, vem sendo debatido ao longo da história, no entanto, é sempre considerado polêmica atual, complexa e envolve aspectos de profundo questionamento, uma vez que, a discussão engloba campos distintos, tais como a ética, a moral, a medicina, o direito, a religião, os costumes e a filosofia (PACHECO, 2007).

Neste contexto, desvelar a história social dos gêneros desde a história primitiva até os dias atuais faz-se necessário; como princípio a nortear e compreender a violência sexual voltada contra a mulher, assim como o surgimento do abortamento na história da sociedade e como se tornou um direito de escolha frente ao abuso sexual.

\section{EVOLUÇÃO HISTÓRICA DA VIOLÊNCIA SEXUAL E ABORTAMENTO}

O longo processo evolutivo que moldou comportamentos sexuais, estendidos até a atualidade, precisa ainda ser compreendido de forma mais abrangente e profundo, onde, reside a raiz de muitos comportamentos e reações do homem para com o homem, em específico, o comportamento da violência sexual oriunda do homem para com a mulher. O processo de evolução da sexualidade humana nasce com o surgimento da vida, há bilhões de anos. Desde então, todo um processo biológico e cultural, foi moldando a forma de viver que se tem atualmente (BARP, 2008).

No acasalamento, anteriormente, a fêmea apresentava-se posterior ao macho atraindo-o para uma breve relação, cuja finalidade era apenas instintiva. O orgasmo feminino emergiu 
em resposta à nova postura. Na posição frente a frente, o rosto começou a ganhar importância entre os sexos. Outro fato importante é a questão do poder, que o macho sentia necessidade de exercer sobre suas fêmeas, a demarcação de seu território, o estabelecimento de uma relação de posse, no sentido da fêmea ser sua propriedade (SPITZNER, 2005).

A sexualidade foi oriunda de uma era primitiva que transita a uma era onde os gêneros começam a tomar papéis sociais e há um desenvolvimento mais complexo do comportamento sexual juntamente com o psicológico.

Há cerca de 500 mil a 10 mil anos a. C. o período Paleolítico se destaca entre as grandes divisões da pré-história (NUNES, 2003). Este período era dominado pelo matriarcado, pelo culto e valorização do elemento feminino e assim permaneceu por milhares de anos. Estas passavam a maior parte de suas vidas grávidas, o que não as impediam de realizar as tarefas de sua rotina. Seus filhos não chegavam a nascer e, dentre as crianças, poucas sobreviviam pelo fato do alto índice de desnutrição, falta de higiene e doenças (SPITZNER, 2005).

Nunes (2003) relata que as mulheres possuíam uma representação simbólica, que se expressa ao nível da religião, das crenças e lendas. Na maior parte do matriarcalismo primitivo há o culto à fertilidade feminina e como consequência a sexualidade a se ver envolvida de uma significação mística, é concebida como sagrada e divina, como o predomínio da função da mulher, como atributo feminino.

Datam deste período as primeiras expressões artísticas que refletem a exaltação dos povos antigos à condição sagrada do corpo da mulher, do homem e, mais precisamente, ao encontro sexual capaz de gerar vida. Há, neste período, extensas produções de pinturas rupestres e esculturas que mostravam o corpo estilizado da mulher e, mais especificamente, a vagina, os seios e o útero. O sexo era um fato natural. O que se tornou algo enigmático e de caráter intocável imposto pela a sociedade e, em ênfase, a religião judaico-cristã (TREVISAN, [SD]; JUSTAMED, 2012).

Quando esta civilização passa a ter manifestações artístico-culturais como as pinturas rupestres, relatadas anteriormente, que reproduzem a vida cotidiana e emblema a mulher e a fertilidade como símbolos e o misticismo, é onde se encontra a origem da transição do Paleolítico para um novo período que se emerge: o Neolítico.

No período neolítico, que se iniciou por volta do ano 9000 a.C., o poder é patriarcal, isto é, a família é dominada pelo homem com a função de pai e chefe. Os homens passaram a controlar o poder real, o exército, o poder religioso e ideológico, assumindo funções sacerdotais e mágicas (SPITZNER, 2005). 
Por volta do III milênio, no início do período bíblico, com a formação do povo Hebreu a visão a respeito da sexualidade modificou-se, o homem delineou a sociedade, fixando a sua supremacia e destinando a mulher a um papel servil, sendo esta sua propriedade (SPITZNER, 2005).

O autor descreve ainda que durante toda a história do povo hebreu a mulher era inferiorizada, desvalorizada e sem espaço na sociedade, dividia os favores sexuais do marido com uma ou mais esposas e concubinas. A esposa hebréia ficaria divorciada se ofendesse o marido e seria apedrejada até a morte se fosse infiel. Com o tempo o cristianismo se expande além das fronteiras de Israel, e o abortamento praticado na cultura Greco-romana que era considerado uma prática comum, agora era visto pelo cristianismo como um pecado. A posição contrária ao aborto é imediatamente tomada assim que se entra em contato com o novo problema.

Deursen (2009) diz que o abortamento não era punido pela lei na sociedade grega, mas muitos filósofos dispendiam seu tempo discutindo o começo da vida. Naquela época, a gravidez só era confirmada ao primeiro movimento do bebê no útero. Aristóteles dizia que o aborto para fins de controle populacional deveria ser realizado antes do surgimento da alma, e que era necessário para evitar o abandono de crianças, corriqueiro na Grécia.

Percebe-se que as concepções sobre o homem e a mulher, oriundas da tradição judaica, influenciaram muito a cultura ocidental através do Cristianismo. Onde encontra-se a base ética das concepções medievais e modernas sobre os dois sexos e sua relação social(NUNES, 2003).

Em Roma, a esposa e filhos constituíam bens dos homens da família. No final do primeiro século a.C., o marido tinha o direito legal de matar a esposa no ato, caso fosse apanhada em adultério. Também poderia divorciar-se caso ela tivesse uma conduta perversa e inaceitável, lassidão moral e sexual ou ser estéril (TREVIZAN, [SD]).

De tal modo abandonar, vender ou matar filhos inesperados era a solução para controlar o tamanho da família romana. Sorano de Éfeso, no século II, defendia o aborto em caso de perigo à saúde da mãe, mas apenas prostitutas e mulheres livres do poder masculino eram independentes para abortar. Interromper a gravidez sem o consentimento do marido e privá-lo de um herdeiro era motivo de separação ou até de pena capital. Os homens se opunham ao aborto porque ele feria o interesse masculino (DEURSEN, 2009).

O direito Romano surge e embasa as leis atuais, sendo Roma a síntese da sociedade antiga, representando um elo entre o mundo antigo e o mundo moderno. Contribui o Direito Romano decisivamente para a evolução do direito penal. Entretanto a violência carnal (coito vaginal) era punida com a morte, considerava-se crime abominável, era avaliado assim, porque 
visava a violência empregada e não o fim do agressor. Neste mesmo período histórico a denominação estupro não era aplicada, pois era usada a palavra stuprum na referida lei que designava como crime a conjunção carnal ilícita com mulher virgem ou viúva honesta, mas tal conjunção não poderia ter violência (PORTILHO, 2005).

No período da República Romana o aborto foi considerado um ato imoral, no entanto, as mulheres o utilizavam principalmente entre aquelas que se preocupavam com a aparência física. De tal modo cresceu o número de abortos a ponto dos legisladores passarem a considerálo um ato criminoso. Como consequência a Lei Cornélia punia a mulher com pena de morte se esta consentisse com a prática abortiva. Já em relação a quem praticasse o ato, aplicava-se a mesma pena, com a possibilidade de abrandamento caso a gestante não falecesse em decorrência das manobras abortivas praticadas (ZAHRA, 2009).

A lenta desestruturação do mundo medieval, a ascensão da burguesia (XVII e XVIII) e a formação de uma visão burguesa, racional, empirista leva à superação das concepções medievais culminando em uma nova era: A Idade Moderna (NUNES, 2003).

Deursen (2009) discorre que ao longo da Idade Moderna (1453-1789), aprendeu-se mais sobre a evolução do feto no útero. Essa percepção, ampliada com a obstetrícia, o estetoscópio, o raio X e o ultrassom, nos 300 anos seguintes, mudou o modo de médicos, políticos e religiosos lidarem com o tema. Mas as mulheres ainda tomavam medicamentos abortivos e recorriam a parteiras.

No século XIII, leis canônicas e civis fortaleceram a distinção entre feto com alma e sem alma, entre um homicídio e um crime menor. A influência da Igreja provoca mudança de foco: não mais o homem e sim o feto devia ser protegido. Porém, nesse debate entre Igreja e legisladores reais sobre o início da vida, faltava à ciência. A descoberta do óvulo, em 1827, transformou a ideia da concepção: agora, a vida começava na fecundação (DEURSEN, 2009).

Por volta de 1920 as mulheres, em quase todos os países, já haviam conquistado o direito de voto. Lutavam por direitos iguais, justiça e igualdade, representando dessa forma, o final da supremacia masculina por mais de 5000 anos (SPITZNER, 2005).

Também em 1920, tem início o movimento pró-aborto atual, com intuitos políticos com Lênin na União Soviética. O primeiro país do mundo a legalizar o aborto com o intuito de segregar raças e conter o crescimento da população (MAGGI, 2010).

A Itália fascista reprimiu o controle de natalidade a partir de 1926. Os nazistas estimularam a reprodução da "raça pura", enquanto tentavam impedir nascimentos entre os povos dominados. Em 1942, no gueto de Kovno, na Lituânia, um decreto condenou à morte todas as judias grávidas. Em 1936, 16 anos após a revolução bolchevique, a União Soviética de 
Stálin voltou a proibir a prática. Em 1943, na França, a parteira Marie-Louise Giraud foi guilhotinada por ter interrompido 26 gestações: o aborto era ameaça ao Estado (DEURSEN, 2009).

Segundo o mesmo autor as décadas seguintes à Segunda Guerra foram de revolução sexual, graças à pílula anticoncepcional. O feminismo surgiu no século 19, e ganhou força, nos anos 60 a prática virou bandeira do direito civil.

Os métodos anticoncepcionais se tornam populares em 1960. Entre os casais, nasce a possibilidade de conceber uma família sem filhos e uma autonomia maior é dada à mulher, que pode se valer de métodos contraceptivos para evitar a gravidez mesmo sem o consentimento ou a cooperação do companheiro (TREVIZAN, [SD]).

Ideias liberais são mais aceitas pela sociedade nesta nova era em que certos aspectos morais não tem mais tanta importância, mas mesmo assim, outros assuntos polêmicos e complexos ainda atormentam a sociedade atual, como o abortamento perante ao estupro. A liberdade sexual aumentou a incidência de casos de estupro e suas queixas registradas. Paralelamente aos altos índices de estupro datados recentemente ocorre o aumento do índice de abortamentos cometidos no mundo.

No Brasil de acordo com estimativas do Ministério da Saúde (2012), entre 729 mil e 1,25 milhões de mulheres se submetem ao abortamento anualmente. Destas, pelo menos 250 morrem.

\section{ABORTAMENTO COMO DIREITO}

O aborto é definido como o produto da concepção eliminado no abortamento, que é a conduta de interrupção da gestação. Todavia, o próprio código penal utiliza desta expressão, aborto, para se referir à criminalização do abortamento. Também é possível utilizar o termo aborto para se referir ao abortamento. Porém, não há como confundir o conceito médico de abortamento com o seu conceito jurídico-penal (BRASILb, 2011).

Para o conceito médico o abortamento se dá quando o peso do embrião não ultrapassa 500 gramas e geralmente isso ocorre por volta de 20 a 22 semanas, com ou não a expulsão do concepto, porém havendo inviabilidade do produto. Subclassificado em aborto precoce quando o aborto ocorre em até 12 semanas e tardio entre 12 e 20-22 semanas. Para a medicina, se ocorre o óbito fetal após as 20-22 semanas é chamado de óbito fetal intra-útero, se o feto com mais de 20-22 semanas nascer com vida e logo após falecer, é chamado de parto prematuro e não aborto (BRASILb, 2011). 
A palavra "aborto" vem do latim abortus, étimo que transmite a ideia de privação do nascimento. De acordo com o significado jurídico é a "interrupção dolosa da gravidez, com expulsão do feto ou sem ela" (PINTO, TOCCI, 2003).

O aborto consiste na expulsão espontânea ou provocada, do embrião ou feto do útero antes do momento em que ele se torna viável. O feto é considerado inviável antes de 20 semanas completas de gestação, sendo o aborto considerado espontâneo quando interrompido natural ou acidentalmente; e provocado, quando por uma ação humana pensada (REBOUÇAS, 2010).

Muitas gestações são interrompidas por decisão pessoal da mulher. Os tipos de abortamento são classificados de acordo com sua procedência - espontâneo ou provocado. O aborto espontâneo consiste naquele em que o próprio organismo se encarrega de realizar. Já o aborto provocado é aquele feito intencionalmente, ocasionando então, a morte do feto por vontade própria, que tem como causador um agente externo, podendo ser esse um profissional ou um leigo (PINTO, TOCCI, 2005).

Os abortamentos podem ser classificados em: ameaça de abortamento, abortamento completo, abortamento inevitável/incompleto, abortamento retido, abortamento infectado, abortamento habitual, abortamento eletivo previsto em lei (BRASILd, 2011).

Existem ainda, outros tipos diferentes de abortamento como o aborto eugênico ou profilático, representando o aborto feito, justificado pela presença de alguma anomalia grave no feto. O aborto social, que é realizado por questão de controle de natalidade. $\mathrm{O}$ aborto terapêutico ou necessário, aquele feito porque a gravidez põe em risco a vida da gestante (REBOUÇAS, 2010).

O aborto decorrente de estupro se enquadra em aborto eletivo previsto em lei como expõe o artigo 128 do Código Penal Brasileiro: "se a gravidez resultante de estupro e o aborto é precedido de consentimento da gestante ou, quando incapaz, de seu representante legal" (VADE MECUM, 2010, p.554).

O abortamento provocado se subdivide em abortamento criminoso, abortamento humanitário e o necessário. Sendo o abortamento eletivo provocado previsto em lei em caso de estupro a principal discussão do presente estudo. Segundo o Código Penal, artigos 124, 125 e 126, considera-se aborto criminoso quando a mulher grávida provoca aborto em si mesma ou consenti que outrem o faça. Quando é provocado por terceiro sem que haja o consentimento da gestante, e quando há o consentimento desta (BRASIL, 2010).

Segundo Capez apud Vianna (2012) o aborto humanitário trata-se do aborto realizado por médicos em casos de gravidez por um estupro. A mulher não é obrigada pelo Estado a gerar um filho fruto de um coito violento. Este tipo de aborto também chamado como aborto pós- 
estupro, aborto sentimental ou aborto ético, é um procedimento lícito, pois a gravidez é resultado do estupro, amparado pelo Código Penal, presente nos artigos 128, inciso II. O estupro é crime tipificado no artigo 213 e 215 do Código Penal. Sendo assim, o aborto provocado ético não é antijurídico (SUDÁRIO, ALMEIDA, JORGE, 2005).

O aborto necessário é definido pelo Código Penal (1940) artigo 128, inciso I "se não há outro meio de salvar a vida da gestante". Este tipo de aborto é realizado quando a gestação oferece risco para a mulher ou quando esta se encontra debilitada ou com alguma patologia.

\section{EPIDEMIOLOGIA DO ESTUPRO E DO ABORTAMENTO}

Os índices de violência contra a mulher são alarmantes. Até o primeiro semestre de 2012, foram feitos 47.555 registros de atendimento na Central de Atendimento à Mulher. Durante todo o ano de 2011, foram 74.984 registros, bem inferior aos 108.491 de 2010, não discernindo violência física de violência sexual (BRASIL, 2012).

Os registros, em sua maior parte, relatam casos de violência como agressão física variando de agressão leve, grave ou gravíssima, tentativa de homicídio e homicídio consumado. Dados apontam 63.838 em 2010, 45.953 em 2011 e 26.939 até julho de 2012. De primeiro de janeiro a 31 de dezembro de 2012, foram 732.468 atendimentos pelo LIGUE 180, o que representa uma média de 2.000 registros por dia. A média mensal foi de, aproximadamente, 61 mil atendimentos, com destaque para o mês de março, com 75.776. Em comparação com 2011, verifica-se um aumento de quase $11 \%$ no total de registros (IBGE, 2013).

Estes dados apontam um avanço nas queixas sobre a violência, porém a denúncia contra a violência sexual é ainda pouco evidenciada e aponta progressos quanto aos dados atuais.

No Brasil, um total de 18.007 mulheres deu entrada no sistema público de saúde em 2012 apresentando indícios de terem sofrido violência sexual. A maioria delas (cerca de 75\%) eram crianças, adolescentes e idosas (IBGE, 2013).

Em paralelo aos índices de violência sexual está o crescente número de abortamento e mortes maternas acometidas por este. Estima-se que a cada ano são feitos 22 milhões de abortamentos em condições inseguras, acarretando a morte de cerca de 47.000 mulheres e disfunções físicas e mentais em outras 5 milhões de mulheres. Um abortamento inseguro é um procedimento para finalizar uma gravidez não desejada, realizado por indivíduos sem as habilidades necessárias e/ou em ambiente abaixo dos padrões médicos exigidos (OMS, 2013). 
Um estudo realizado em 2010 com 2.002 mulheres alfabetizadas com idades entre 18 e 39 anos mostra a magnitude do abortamento no Brasil urbano. Ao final da vida reprodutiva, mais de uma em cada cinco mulheres sofreram aborto, ocorrendo os abortos em geral nas idades que compõem o centro do período reprodutivo das mulheres, isto é, entre 18 e 29 anos (DINIZ, MEDEIROS, 2010).

Segundo Diniz e Medeiros (2010) o número de abortos é, seguramente, superior ao número de mulheres que fizeram aborto. Essa proporção varia de $6 \%$ para mulheres com idades entre 18 e 19 anos a $22 \%$ entre mulheres de 35 a 39 anos. Isso mostra o quanto o aborto é um fenômeno comum na vida reprodutiva das mulheres. Cerca de $60 \%$ das mulheres fizeram seu último (ou único) aborto no centro do período reprodutivo, isto é, entre 18 e 29 anos, sendo o pico da incidência entre 20 e 24 anos ( $24 \%$ nesta faixa etária apenas). O aborto é mais frequente entre mulheres de escolaridade muito baixa aproximadamente $23 \%$ entre aquelas com até o quarto ano do ensino fundamental (ou nível equivalente), ao passo que entre mulheres com o ensino médio concluído é de $12 \%$.

Os dados encontrados mostram que o abortamento é uma prática muito comum no mundo e no Brasil gerando consequências de saúde que coloca o abortamento em posição de destaque e de prioridade as preocupações de saúde pública. Estes índices não especificam o tipo de abortamento provocado.

\section{ABORTO E ESTUPRO: CONSEQUÊNCIAS FÍSICAS E PSICOLÓGICAS}

Após a mulher ter passado pelo sofrimento do abuso sexual ela se depara com consequências físicas como os traumas genitais e extragenitais, hematomas e lacerações genitais, além das doenças sexualmente transmissíveis (DST). A prevalência de DST em situações de violência sexual é elevada, e o risco de contágio depende de diversas variáveis, como o tipo de violência sofrida (vaginal, anal, oral), o número de agressões, o tempo de exposição (única, múltipla ou crônica), a ocorrência de traumatismos genitais, a idade e suscetibilidade da mulher, a condição himenal (BRASILa, 2011).

Mulheres que passaram pela violência de um estupro lidam com um temor ainda maior que é de gerar um filho de seu agressor. A gravidez indesejada se destaca pela complexidade das reações psicológicas, sociais e biológicas, sendo assim, encarada como uma segunda forma de violência. Muitas destas mulheres que se encontram nesta situação acabam procurando por serviços clandestinos para fazer o abortamento.

As consequências físicas do abortamento são inúmeras destacando-se a perfuração uterina - podendo resultar em uma histerectomia, dilaceração cervical, câncer de mama, câncer 
cervical, do ovário e do fígado, doença inflamatória pélvica (PID), endometriose e a morte por infecção sanguínea, acidentes anestésicos, gangrena espontânea dos ovários. Outras consequências podem advir de um abortamento mal feito, tais como, hemorragia grave, infecções, retenção de restos de placenta, esterilidade, peritonite, tétano, septicemia, trauma psicológico, muitas vezes chegando até o suicídio (PINTO, TOCCI, 2013; BRASILa, 2011).

Além das possíveis consequências físicas, um aborto costuma provocar crises de arrependimento e culpa, e reações psiconeuróticas e distúrbios emocionais como: remorso, oscilações de ânimo e depressões, choro imotivado, medos e pesadelos, queda na autoestima pessoal pela destruição do próprio filho, frigidez (perda do desejo sexual), aversão ao marido ou ao amante, culpabilidade ou frustração de seu instinto materno, desordens nervosas, insônia, transtornos sexuais, transtorno de estresse pós-traumático, ansiedade, entre muitos outros, e esses traumas podem influir na vida profissional, sexual, afetiva e social das vítimas (PINTO, TOCCI, 2003).

\section{CONSIDERAÇÕES FINAIS}

A violência sexual atinge números alarmantes no Brasil e no Mundo, o abortamento é um direito da vitima em casos de estupro, porém o ato pode gerar conflitos internos e somar maiores conseqüências às vitimas. $\mathrm{O}$ estudo possibilitou a discussão e o conhecimento sobre os aspectos legais que envolvem as vitimas de violência sexual e a decisão pelo abortamento.

\section{REFERÊNCIAS}

BARP, M. R. T. Sexualidade e educação: o conflito entre o cultural e o biológico na atuação educador. Visão Global, v. 11, n. 2, p.163-178. 2008.

BENITES, A. Com registro de 37 estupros por dia, São Paulo vai mapear criminosos. Folha de São Paulo, São Paulo, 28 mai. 2013. Disponível em: <http://www1.folha.uol.com.br/cotidiano/2013/05/1285946-com-37estupros-por-dia-saopaulo-vai-mapear-criminosos.shtml>. Acesso em: 15 set. 2013.

BRASIL. Presidência da República, Secretaria de políticas para as mulheres, Central de Atendimento à Mulher - Ligue 180 Dados Consolidados. 2012. Disponível em: http://www.spm.gov.br/ouvidoria/central-de-atendimento-a-mulher $>$. Acesso em: 13 out. 2013. 
BRASILa. Ministério da Saúde, Secretaria de Atenção à Saúde. Prevenção e tratamento dos agravos resultantes da violência sexual contra mulheres e adolescente: norma técnica. 3 . Ed., Brasília. Ministério da Saúde. 2011. 123p.

BRASILb. Ministério da Saúde. Secretária de Atenção à Saúde. Departamento de Ações Pragmáticas estratégicas. Aspectos jurídicos do atendimento às vítimas de violência sexual: perguntas e respostas para profissionais de saúde. 2 . Ed. Brasília, editora do Ministério da Saúde, 2011.

DEURSEN, F. V. Aborto: o começo do fim. Revista Aventuras da História. 2009. Disponível em: http://guiadoestudante.abril.com.br/aventuras-historia/aborto-comeco-fim-476693.shtml Acesso em: 20 set. 2013.

DINIZ, D.; MEDEIROS, M. Aborto no Brasil: uma pesquisa domiciliar com técnica de urna. Ciência \& Saúde Coletiva. Brasília, v. 15, n.1, p. 959-66. 2010.

IBGE. Instituto Brasileiro Geografia e Estatística. Brasil, 2013. Disponível em: <http://teen.ibge.gov.br/noticias-teen >. Acesso em: 29 set. 2013.

JUSTAMAND, M. O feminino rupestre em São Raimundo Nonato (Piauí): muito antes de 1500. (Tese). 2012. Disponível em: <http://www.sapientia.pucsp.br/tde busca/arquivo.php?codArquivo=5578> Acesso em: 20 set. 2013.

MENUCUCCI, E. 01/08 - Nota da ministra Eleonora Menucucci sobre a sanção do PLC 03/2013. Secretaria Especial de Políticas para as Mulheres. Brasília, 01 ago. 2013. Disponível em: <http://www.spm.gov.br/noticias/ultimas noticias/2013/08/01-08-2013-nota-da-mini straeleonora-menicucci-sobre-a-sancao-do-plc-03-2013-1/?searchterm $\quad=a \% \quad 20 \quad$ ca da\%2012\%20segundos>. Acesso em: 14 mai. 2014.

NUNES, C. A. Desvendando a Sexualidade. 7. ed. Campinas: Papirus, 2003.

OMS. Organização Mundial de Saúde (Suíça). Abortamento seguro: Orientação Técnica e de Políticas para Sistemas de Saúde. 2013. 2. ed. p. 1. Disponível em: <http://apps.who.int/iris/bitstream/10665/70914/7/9789248548437 por.pdf.> Acesso em: 21 out. 2013. 
PACHECO, E. D. O aborto e sua evolução histórica. Aspectos mais relevantes do aborto ao longo de sua evolução histórica, trazendo noções básicas de períodos distintos, desde o início das civilizações até a atualidade. 2007. Disponível em: <http://www.direitonet.com.br/artigos/exibir/3764/O-aborto-e-sua-evolucao-historica.>

Acesso em: 10 set. 2013.

PINTO, A. P.; TOCCI, H. A. O aborto provocado e suas consequências. Rev Enferm, v.4, p.56-61. 2003.

PORTINHO, J. P. C. História, Direito e violência: do estupro e atentado violento ao pudor Aspectos gerais. História e história, ago, 2005. Disponível em: $<$ http://www.historiaehistoria.com.br/materia.cfm?tb=alunos\&ID=10. $>$ Acesso em: 20 set. 2013.

REBOUÇAS, M. S. S. O aborto provocado como uma possibilidade na existência da Mulher: Reflexões fenomenológicos-existenciais. (Dissertação). Natal: Universidade Federal do Rio Grande do Norte, 2010. Disponível em: <http://bdtd.bczm.ufrn.br/tde arquivos/1/TDE2010-12-08T102715Z-3122/Publico/ MelinaSSRDISSERT.pdf.>Acesso em: 13 out 2013.

SPITZNER, R. H. L. Sexualidade e Adolescência: Reflexões acerca da Educação Sexual na escola. (Dissertação). Maringá: Universidade Estadual de Maringá, 2005. Disponível em: <http://www.ppe.uem.br/dissertacoes/2005-ReginaSpitzner.pdf.> Acesso em: 29 set. 2013.

SUDÁRIO, S; ALMEIDA, P. C; JORGE, M. S. B. Mulheres Vítimas de Estupro: Contexto e Enfrentamento dessa Realidade. Psicologia \& Sociedade. v.17 n. 3, p.73-79, set-dez. 2005.

TREVISAN, R. A sexualidade humana: uma visão histórico-social. (Tese). São Paulo: Universidade Metodista de São Paulo, [200-?]. Disponível em: $<$ http://www.cursoraizes.com.br/resources/a-sexualidade-humana.pdf. $>$ Acesso em: 18 set. 2013.

VADE MECUM. Código Penal. Saraiva. Ed. Saraiva, 10ª edição. 2010.

VIANA, A. C. N. Aborto. (Monografia). Barbacena: Universidade Presidente Antônio Carlos. 2012. Disponível em: <http://www.unipac.br/bb/tcc/tcc-81131ca

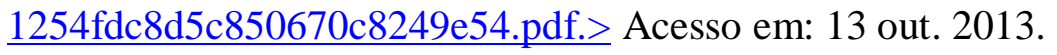

ZAHRA, M. A. Políticas públicas de planejamento familiar e a Contenção do aborto ilegal. (Monografia). Dourados. MT: Universidade Estadual do Mato Grosso do Sul - UEMS. 2009. Disponível em: <http://www.uems.br/portal/biblioteca/repositorio /2012-02-06 09-3943.pdf.> Acesso em: 13 out. 2013. 
